\title{
Sentinel Lymph Node Biopsy in Early Breast Cancer: The Experience of the European Institute of Oncology in Special Clinical Scenarios
}

\author{
Antonio Toesca Alberto Luini Paolo Veronesi Mattia Intra Oreste Gentilini \\ Division of Breast Surgery, European Institute of Oncology, Milano, Italy
}

\section{Keywords}

Sentinel node $\cdot$ Breast cancer - Axillary dissection . Axillary staging

\section{Summary}

Background: While axillary nodal status is still one of the most important prognostic factors in breast cancer, sentinel lymph node biopsy (SLNB) has evolved as a main procedure to strongly reduce postsurgical morbidity improving early and long-term quality of life. Material and Methods: Between 1996 and 2010, we performed 18,884 SLNBs for breast cancer, successfully confirming the validity of this technique and its positive impact on patients' quality of life, even though decision-making processes for adjuvant treatment strongly depend on biological features. Results: This paper summarizes published data mainly collected in our institute considering special clinical scenarios such as ductal intraepithelial neoplasia, intramammary sentinel nodes, multicentric breast cancer, prior breast surgery, previous breast aesthetic surgery, second axillary SLNB, pregnant patients, primary chemotherapy, and male patients. Conclusions: In general, we believe that SLNB represents the standard procedure for axillary staging in virtually all clinical situations, even in those which were previously considered a contraindication for this procedure. At the moment, the only contraindication to SLNB is the presence of documented axillary metastases.

\author{
Schlüsselwörter \\ Sentinel-Lymphknoten · Mammakarzinom . \\ Axilladissektion · Axillastaging
}

\section{Zusammenfassung}

Hintergrund: Während der Lymphknotenstatus in der Axilla weiterhin einer der wichtigsten Prognosefaktoren beim Mammakarzinom ist, hat sich die Sentinel-Lymphknoten-Biopsie (sentinel lymph node biopsy, SLNB) zu einer der Hauptmethoden zur weitreichenden Reduktion der postoperativen Morbidität und Verbesserung der kurz- und langfristigen Lebensqualität entwickelt. Material und Methoden: Zwischen 1996 und 2010 wurden an unserer Institution 18884 SLNBs bei Mammakarzinompatientinnen durchgeführt und damit die Validität und der positive Einfluss der Methode auf die Lebensqualität der Patienten bestätigt, obgleich Entscheidungsvorgänge zur adjuvanten Therapie stark von biologischen Eigenschaften des jeweiligen Tumors abhängig sind. Ergebnisse: Der vorliegende Artikel fasst publizierte Daten zusammen, die hauptsächlich an unserer Institution gesammelt wurden, unter Einbeziehung spezifischer klinischer Szenarien wie duktale intraepitheliale Neoplasien, intramammäre Sentinel-Knoten, multizentrische Mammakarzinome, vorherige Brustoperationen, vorherige ästhetische Operationen an der Brust, zweite axilläre SLNB, schwangere Patientinnen, primäre Chemotherapie und männliche Patienten. Schlussfolgerungen: Wir sind der Überzeugung, dass SLNB die Standardmethode für das Axillastaging in praktisch allen klinischen Situationen ist, einschließlich derer, die in der Vergangenheit als Kontraindikationen für SLNB galten. Die einzige momentane Kontraindikation ist das Vorliegen von dokumentierten Axillametastasen.

\section{KARGER \\ Fax +497614520714 \\ Information@Karger.de}

www.karger.com (c) 2011 S. Karger GmbH, Freiburg

$1661-3791 / 11 / 0063-0208 \$ 38.00 / 0$

Accessible online at:

www.karger.com/brc
Oreste Gentilini, MD

European Institute of Oncology

Division of Breast Surgery

Via Ripamonti 435, 20141 Milano, Italy

Tel. +39 02-5748 9376 947, Fax -94379228

oreste.gentilini@ieo.it 


\section{Introduction}

While axillary nodal status is still one of the most important prognostic factors in breast cancer, sentinel lymph node biopsy (SLNB) has evolved as a main procedure to strongly reduce postsurgical morbidity improving early and long-term quality of life. Moreover, the decision-making process for adjuvant treatment based on axillary status is still important but so far this choice is becoming increasingly dependent on biological features rather than on the risk of recurrence in terms of selecting the treatment having the highest probability of response. This vision imposes the necessity to reduce the indication of complete axillary dissection as much as possible, especially whenever the axilla is clinically negative. At the European Institute of Oncology (IEO) in Milan, between 1996 and 2010, we performed 18,884 SLNBs for breast cancer, successfully confirming the validity of this technique and its positive impact on patients' quality of life. In this paper, we summarize published data mainly collected in our institute concerning SLNB and its application in special clinical scenarios.

\section{Material and Methods}

\section{Patients}

Between 1996 and 2010, 18,884 SLNBs for breast cancer were carried out at the IEO in Milan.

\section{Lymphoscintigraphy and SLNB}

Lymphoscintigraphy was performed in all cases using our standard technique previously described [1-3]. Five to $10 \mathrm{MBq}$ of technetium-99mlabeled particles (50-200 nm) of human colloidal albumin (Nanocoll, GE Healthcare, Milan, Italy) in $0.2 \mathrm{ml}$ saline is injected close to the tumor [4, 5] or in a subcutaneous projection area. From 15-30 min after radiotracer injection, anterior and anterior-oblique lymphoscintigraphic projections of the breast and axilla are then obtained to precisely locate the sentinel lymph node (SLN). SLNB is performed 4-20 h after radioactive tracer injection. A gamma ray-detecting probe in a sterile glove is used to identify the 'hot' SLN and assist in its removal during surgery. During breast conservative surgery, if the tumor is in the upper-outer breast quadrant, the breast incision is extended to the SLN in the axilla using the probe as guide. In other cases, generally, a separate incision for SLNB is necessary. SLNB is also performed during total or nipple-sparing mastectomy, in these cases, through the same surgical cavity. All SLNs removed are sent for intraoperative extensive frozen-section analysis.

\section{Pathology}

Pathological examination of the SLN is routinely performed with a complete and extensive intraoperative analysis, without any portion of nodal tissue left for fixation and paraffin-embedding. This analysis requires 30-45 min and is very demanding in terms of time, experience, and human resources. However, it allows a complete and final answer to be obtained directly during surgery, thereby avoiding the risk of a second operation in case an involvement of the SLN is found after an initially negative intraoperative report. Any one of the SLN is cut into 60 sections (30 pairs), cut at $50 \mu \mathrm{m}$ intervals. Whenever residual tissue is left, additional pairs of sections are cut at $100 \mu \mathrm{m}$ intervals. One section of each pair is routinely stained with hematoxylin and eosin $(\mathrm{H}$ and $\mathrm{E})$. If results are doubtful, the mirror sections are immunostained for cytokeratin, using a rapid method involving monoclonal anti-cytokeratine antibody (DAKO, Copenhagen, Denmark) [6-8].

\section{Findings and Discussion}

\section{Long-Term Observation}

The 10-year follow-up results of a prospective randomized controlled study were recently published [1]. In this trial, we enrolled 516 patients with T1 primary breast cancer. A group of patients who underwent SLNB plus immediate complete axillary dissection was compared with a group who underwent axillary dissection just in case of SLN metastasis. The cumulative incidence of axillary metastasis in the SLN group was lower than expected (2 of 259 patients) (fig. 1). Overall survival was similar between the 2 groups of patients.

We recently reported the outcome of a large cohort of patients with a negative SLNB [6]. A total of 3,548 patients treated from 1996 to 2004 with negative SLN, who did not receive axillary dissection, were followed for up to 11 years with a median follow-up of 48 months. Among these 3,548 patients, the 5-year cumulative incidence was $10.1 \%$ (95\% confidence interval (CI) $8.9-11.3 \%$ ) with a median time to recurrence of 29 months. In all these patients, axillary dissection was performed. The cumulative incidence of axillary metastasis at 5 years was $1.0 \%$ (95\% CI $0.6-1.4 \%$ ), significantly lower than what was expected under the assumption that approximately $5-6 \%$ of non-sentinel axillary nodes would be positive and would become clinically evident occurring at a constant rate over a 12-year time interval (fig. 2).

\section{Ductal Intraepithelial Neoplasia}

Axillary staging in breast 'in situ' pathology is still a matter of debate despite the fact that by definition, it is not possible for ductal intraepithelial neoplasia (DIN) or ductal carcinoma in situ (DCIS) to metastasize either to distant organs or to locoregional lymph nodes, as they lack the invasive component. Nevertheless, a minimal rate of axillary involvement is commonly described in patients with intraductal neoplasia as well. SLNB represents a good opportunity, for selected cases, to stage patients with a preoperative diagnosis of intraductal neoplasia [9].

Intra et al. [10] in 2008 reported a series of 854 selected patients affected by truly pure DCIS, who received lymphoscintigraphy and SLNB. SLN metastases were detected in 12 of the 854 patients $(1.4 \%)$ and isolated tumor cells (ITC) were identified in 4 additional patients.

The risk of node metastasis does not seem to be correlated with sub-histotype, necrosis, nuclear grade, hormone receptor status, Her2/neu status, KI-67, multifocality, or type of sur- 


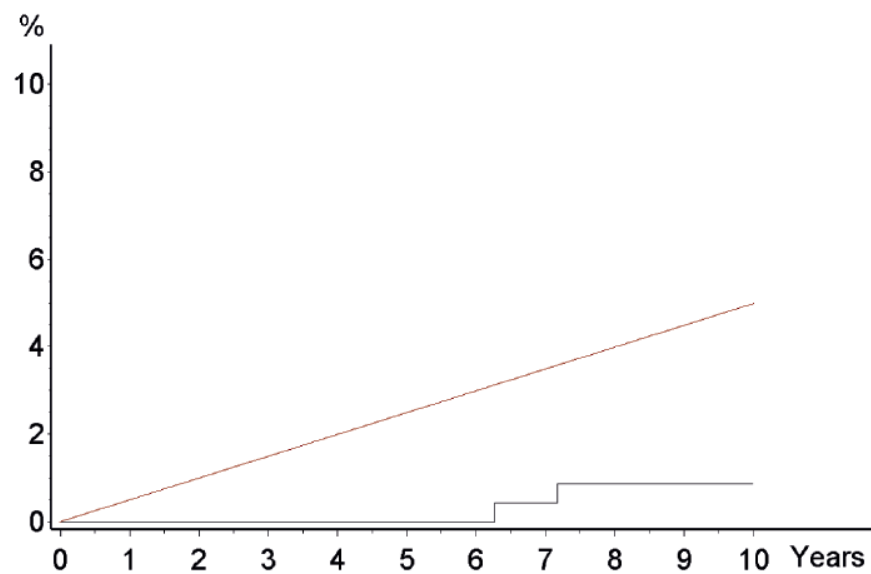

Fig. 1. Observed (gray line) and expected (red line) axillary metastasis over time in patients with negative sentinel node [1]. Expected cumulative incidence of axillary metastasis in SN group patients who did not receive $\mathrm{AD}$, assuming that approximately $5 \%$ of non-sentinel axillary lymph nodes are metastatic, that all metastatic nodes become clinically evident, and do so at a constant rate over the 10-year follow-up.

gery. Only age (younger than 50), clinical presentation (mass on screening or palpable lesion), and tumor size (median size $30 \mathrm{~mm}$ ) seem to be important in predicting the risk of locoregional metastasis. Therefore, SLNB should not be considered a standard procedure in the treatment of all patients with intraductal neoplasia. If the diagnosis is sufficiently guaranteed, regardless of the histology, tumor grade, age, clinical presentation, and tumor size, SLNB should be avoided. This happens when the lesion is completely excised by surgery, or totally removed by core needle biopsy or vacuum assisted biopsy.

The sole criteria for proposing SLNB in patients with a preoperative diagnosis of intraductal neoplasia should be uncertainty regarding the presence of invasive foci at the final histological examination. This happens in cases where the lesion is not completely excised by conservative surgery (positive margins of resection or residual microcalcifications at postoperative mammogram), or in large solid tumors, or diffuse or pluricentric microcalcifications not macroscopically removed by vacuum-assisted biopsy. In such cases, the risk of invasion at the final histological examination is related to the tumor size, and ranges from 10 to $20 \%$ [11]. Whenever mastectomy is required, in our opinion, SLNB is strongly recommended in order to avoid the risk of a second operation.

\section{Intramammary Sentinel Node}

The presence of intramammary sentinel nodes (intraMSNs) on preoperative lymphoscintigraphy is becoming a more common finding in the clinical setting. There is no consensus in the international literature on how to interpret information provided by an intraMSN biopsy when making surgical deci-

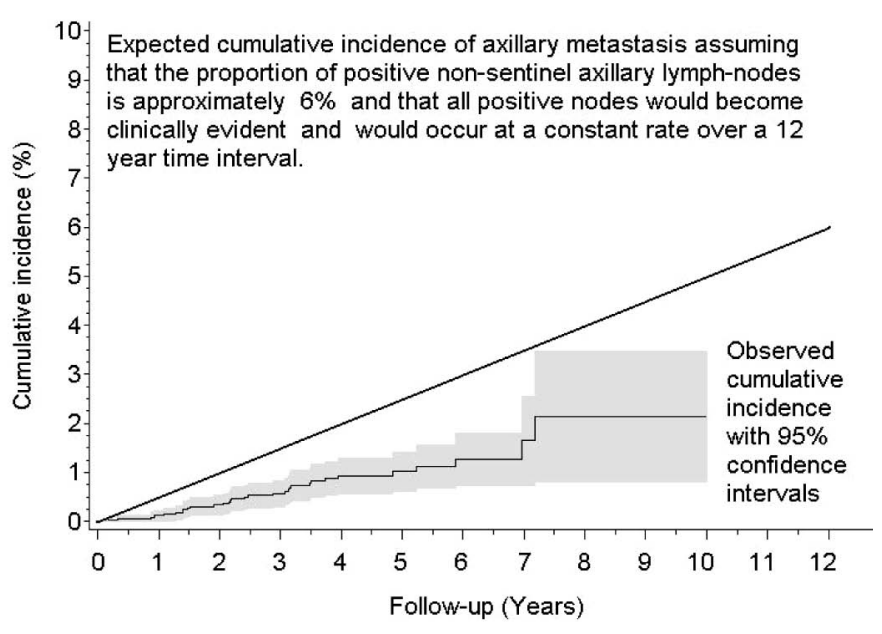

Fig. 2. Development of axillary metastasis $(n=31)$ in 3,548 women with sentinel node-negative breast cancer [6].

sions. The argument lies in whether or not a positive intraMSN imposes the necessity for an axillary dissection or whether it can be spared $[12,13]$.

Between December 2001 and September 2006, 9,632 patient records in the IEO database were retrospectively reviewed by Intra et al. [14]. In 22 patients $(0.2 \%)$, an intraMSN in association with the axillary SLN was documented. The intraMSN was not identified at surgery in 4 cases, and in 3 cases the surgeon decided not to excise it. In the remaining 15 cases, both the axillary SLN and the intraMSNs were simultaneously excised. Positive intraMSNs were found in 6 patients, 3 of which were micrometastatic. In 9 patients, the intraMSN was negative. The axillary SLNB proved to be negative in all 15 patients. Two cases with positive intraMSNs and 1 case with a negative intraMSN underwent axillary dissection, and all axillary nodes were negative. After 24 months, no axillary relapse was identified.

We concluded that when both intraMSNs and axillary SLN are present, then both should be biopsied but axillary dissection should be based solely on the status of the axillary SLN. Our routine policy is that a positive intraMSN with negative axillary SLN does not justify axillary dissection. When lymphoscintigraphy reveals a 'hot' intraMSN, we recommend that it be sought and removed if technically feasible, in order to have an additional prognostic factor and to have better local control. Frozen section may be avoided, however, as it does not change the axillary surgical approach.

\section{Multicentric Breast Cancer}

Several studies have been published showing the success rate, sensitivity, negative predictive value, and accuracy of SLNB 
in multicentric breast cancer being similar to those in unifocal breast cancer [15, 16]. In 2006, Gentilini et al. [17] published a report of 42 patients with multicentric breast cancer submitted to SLNB and axillary dissection performed just in case of nodal metastasis. 25 patients underwent a single subareolar injection, double peritumoral/subdermal injection was administered in 17 patients. The identification rate was $100 \%$. The mean number of SLN identified was similar in patients who received single or double injections. In this study, no overt axillary recurrence occurred after a median follow-up of 24 months. At our institute, we routinely perform SLNB in patients with multicentric disease and a clinically negative axilla, in most cases by using a single subareolar injection of radiotracer. In some circumstances, when 2 peripheric tumors are present, a double peritumoral injection can also be considered in order to rule out extra-axillary drainage. We always recommend a careful intraoperative exploration of the axilla in order to decrease the risk of false-negative SLN findings.

\section{Prior Breast Surgery}

From June 1997 to January 2004, 543 patients underwent a breast biopsy [18]. These patients received SLNB by lymphoscintigraphy performed subdermally on the previously affected area between the scar and the axilla. The SLN was identified in $99 \%$ of cases. In $70 \%$ of cases, the SLN was negative. Among the 161 patients with positive SLN, this was the only positive node in $61.5 \%$ of cases. After a median followup of 2 years, 4 nodal recurrences were observed and were treated with axillary dissection. In our opinion, SLNB is feasible and is routinely performed after previous conservative surgery and can be considered even after total mastectomy [19].

\section{Previous Breast Aesthetic Surgery}

Between April 2001 and June 2007, 70 patients with previous breast aesthetic surgery underwent SLNB. 50 had a previous breast augmentation and 20 had breast reduction mammoplasty [20]. Lymphoscintigraphy identified the SLN in all 70 patients $(100 \%)$. Overall, 72 SLN were identified since 1 patient underwent a bilateral lymphoscintigraphy for a bilateral tumor and 1 patient showed bilateral axillary drainage and drainage to the ipsilateral internal mammary chain. Forty-nine patients $(65 \%)$ had negative SLN. Two patients (3\%) had isolated tumor cells; 23 patients $(32 \%)$ had a positive SLN, 5 of which had micrometastasis only. After a median follow-up of 19 months, no axillary recurrences were observed. We concluded that independent of the previous surgical approach, a history of aesthetic surgery is not a contraindication for SLNB.

\section{Second Axillary Sentinel Node Biopsy}

Between January 2000 and October 2006, 65 patients showing an invasive ipsilateral breast tumor recurrence without palpable axillary nodes were offered a second SLNB [21]. 47 women had invasive carcinoma and 18 DCIS at primary surgery. In 63 patients, preoperative lymphoscintigraphy showed at least 1 new axillary SLN (identification rate 97\%). In 5 of these 63, in association with the axillary SLN, extraaxillary drainage was documented: supraclavicular in 1 patient and internal mammary in 4 patients. After a median follow-up of 45 months, there were no axillary recurrences in any of the 57 patients who did not have complete axillary dissection. It is difficult to quantify the minimum required interval between the first and second SLNB since the time of effective restoration of the lymphatic drainage anatomy is unknown. Nevertheless, a very early breast recurrence is probably residual disease rather than true recurrence. In these patients, the first SLNB maintains the same predictive value for both the first tumor and the early recurrence, and a second SLNB might not be indicated. In that series, 6 months was considered the minimum interval necessary from the first SLNB before proposing a second one. Regardless of whether radiotherapy was carried out or not, the SLN identification rate remained high $(97 \%)$.

\section{Pregnant Patients}

A previous simulation study [22] demonstrated that the dose of radiation to the fetus is minimal during lymphoscintigraphy. Currently, we also offer SLNB to women with breast cancer diagnosed during pregnancy since a review of the dosimetric evaluations reported in the literature as well as our data from a simulation study show evidence that the risks to the fetus are negligible. Between April 2001 and September 2007 [23], we managed 45 patients with breast cancer diagnosed during pregnancy, who were entered into our dedicated database. Only 12 patients were candidates for SLNB. The 12 pregnancies resulted in 11 babies with normal weight according to the gestational age and no malformation, who were all born after uncomplicated pregnancies. One baby, who was born at the 34 th week by means of caesarean section, was operated on at the age of 3 months for cardiac failure due to a perimembranous subaortic ventricular septal defect (VSD). However, the VSD was suspected at the morphological ultrasound scan which was performed during the 21st week of gestation, and lymphoscintigraphy was performed during the 26th week. A subsequent a posteriori evaluation by a different observer performed on video material confirmed the suspicion of a VSD. After a median follow-up of 32 months (range 6-83 months), all the babies were doing well at the time of follow-up. No overt axillary lymph node reappearance of the disease had occurred in patients with negative nodes. 
As in any medical procedure, the decision must take into consideration the overall risk-benefit balance. Although caution is always recommended in any technique involving radiation - the protection of the baby being the major concern - we believe that the results available in the literature provide sufficient evidence to exclude any reasonable risk to the fetus from SLNB by using our standard technique. Further optimization can be obtained by lowering the time interval between injection and surgery (e.g. 2-4 h), allowing lower activity to be injected (e.g. 3-5 MBq) and shorter exposure from the radioactivity trapped in the tumor.

\section{Primary Chemotherapy}

Primary chemotherapy for operable breast cancer is administered to reduce primary tumor extent in order to enhance the possibility of breast conservative surgery and, no less important, to evaluate the 'in vivo' response to chemotherapeutic drugs. Several studies have questioned the feasibility of SLNB in patients treated with preoperative chemotherapy, the main concern being that the accuracy of the technique after chemotherapy treatment might be diminished with an increase in the false-negative rate. On the other hand, many studies have demonstrated that the identification and false-negative rates of SLNB are similar to those reported in the absence of preoperative chemotherapy $[24,25]$. In one of the largest studies on this topic (National Surgical Adjuvant Breast and Bowel Project multicentric trial B-27) [26], there were non-significant differences in false-negative rate according to clinical patient and tumor characteristics, method of lymphatic mapping, or tumor response to chemotherapy. A meta-analysis concerning SLNB after preoperative chemotherapy was published including 21 papers for a total of 1,273 patients [27] The identification rate ranged from 72 to $100 \%$, with a pooled estimate of $90 \%$. The sensitivity of SLNB ranged from 67 to $100 \%$, with a pooled estimate of $88 \%$. These results are comparable to those obtained from multicenter studies evaluating SLNB before systemic therapy and suggest that SLNB is applicable following neo-adjuvant chemotherapy. Therefore, in women with a clinically negative axilla before the start of neoadjuvant chemotherapy, SLNB might be considered after the completion of medical treatment if no progression has occurred.

In patients with suspicious axillary nodes at presentation which have been 'downstaged' to N0 by medical treatment, SLNB might also be considered an option after proper diagnostic preoperative evaluation. SLNB is obviously not recommended for patients whose axillary nodes remain clinically suspicious after chemotherapy. Positron emission tomography (PET) scan might be a useful tool for properly selecting those patients in whom SLNB can be performed, even though this still represents a matter of research [28].

\section{Male Patients}

Between April 1999 and January 2005, 75 men with breast cancer were treated at the European Institute of Oncology. Forty-three patients had a contraindication of clinically positive axillary nodes. A retrospective analysis of the remaining 32 patients with clinically negative axillary lymph nodes, who had had an SLNB, was carried out [29]. Lymphoscintigraphy and subsequent imaging successfully identified axillary hot spots in all patients with a mean number of 1.3 (range 1-2). The SLN was identified in all patients, and a total of 48 nodes were removed, with a mean number of 1.5 SLN per patient (range 1-3). 26 patients had negative SLN. Metastases were found in 4 patients, and micrometastases were found in the remaining 2 patients. After a median follow-up of 30 months (range 1-63), no events related to breast cancer or to overt axillary reappearance of the tumor occurred during this period.

\section{Conclusions}

SLNB has become the standard approach for axillary staging in patients with breast cancer worldwide. This procedure yields the same staging power as axillary lymph node dissection with less complications and better quality of life [30]. This less invasive procedure is possible for several reasons: i) Removal of lymph nodes is performed for staging purposes and not with curative intent [31-33], therefore, the wellknown risk of having a false-negative result can be accepted and comprehended; ii) even if the false-negative risk can be generally quantified in about $6 \%$, the occurrence of overt axillary lymph node metastases after a negative SLNB has been shown to be lower than expected, being $0.9 \%$ after a median follow-up of 48 months in a cohort of 3,548 patients [6]; iii) to date, the impact of the prognostic information of axillary lymph node status in the decision-making process is less important than in the past as the adjuvant treatment is becoming increasingly tailored towards the biological features of the disease rather than the risk of recurrence.

The introduction of SLNB represented a revolution and one of the latest innovations on the path of minimizing the surgical approach to breast cancer patients. As it is a functional concept rather than an anatomical entity, SLNB can be applied also to special clinical scenarios in which lymphatic drainage might be different than under physiologic conditions.

As previously mentioned, we also have to bear in mind that lymph node surgery is not curative in itself and has the aim of improving regional control of the disease and of achieving prognostic information. From this standpoint, the future evolution of lymph node surgery will probably be in the direction of further reduction since medical treatment will be more tailored in accordance with tumor biology rather than recurrence risk, especially when better diagnostic tools become available. 
A recent publication with data taken from the first 566 patients with positive SLN of the AMAROS trial [34] did not find any significant differences in terms of administration of adjuvant systemic therapy. The authors concluded that the absence of knowledge regarding the extent of nodal involvement in the axillary radiation therapy (ART) arm appeared to have no major impact on the administration of adjuvant treatment. The findings of the American College of Surgeons Oncology Group Z0011 trial push ahead the field of controversy [34]. In fact, in this trial, which compared axillary clearance with observation in patients with SLN involvement, outcome appeared identical in the 2 groups in terms of overall survival, disease-free survival, and axillary recurrence. Those arguments are in favor of minimizing axillary surgery.

Based on all these considerations, we do not believe that it is necessary to validate SLNB in advance in every special clinical setting, and we apply SLND virtually in all clinical situations even in those which were previously considered a contraindication for this procedure. Basically, our policy is to perform SLNB always unless documented axillary metastases are present.

\section{Acknowledgement}

The authors are greatly thankful to AIRC (Associazione Italiana pel la Ricerca contro il Cancro) who supported the clinical research on SLNB. The authors also wish to thank Mr. William Russell-Edu for his help with the English language.

\section{Disclosure Statement}

The authors deny any sponsorship or funding arrangement and have no conflicts of interests to declare.

\section{References}

1 Veronesi U, Viale G, Paganelli G, Zurrida S, Luini A, Galimberti V, Veronesi P, Intra M, Maisonneuve P, Zucca F, Gatti G, Mazzarol G, De Cicco C, Vezzoli D: Sentinel lymph node biopsy in breast cancer: ten-year results of a randomized controlled study. Ann Surg 2010;251:595600

$\checkmark 2$ Giuliano AE, Kirgan DM, Guenther JM, Morton DL: Lymphatic mapping and sentinel lymphadenectomy for breast cancer. Ann Surg 1994;220:391-8; discussion 398-401.

3 Krag D, Weaver D, Ashikaga T, Moffat F, Klimberg VS, Shriver C, Feldman S, Kusminsky R, Gadd M, Kuhn J, Harlow S, Beitsch P: The sentinel node in breast cancer - a multicenter validation study. N Engl J Med 1998;339:941-6.

4 De Cicco C, Cremonesi M, Luini A, Bartolomei M, Grana C, Prisco G, Galimberti V, Calza P, Viale G, Veronesi U, Paganelli G: Lymphoscintigraphy and radioguided biopsy of the sentinel axillary node in breast cancer. J Nucl Med 1998;39:2080-4.

5 Paganelli G, De Cicco C, Cremonesi M, Prisco G, Calza P, Luini A, Zucali P, Veronesi U: Optimized sentinel node scintigraphy in breast cancer. Q J Nucl Med 1998;42:49-53.

6 Veronesi U, Galimberti V, Paganelli G, Maisonneuve P, Viale G, Orecchia R, Luini A, Intra M, Veronesi P, Caldarella P, Renne G, Rotmensz N, Sangalli C, De Brito Lima L, Tullii M, Zurrida S: Axillary metastases in breast cancer patients with negative sentinel nodes: a follow-up of 3,548 cases. Eur J Cancer 2009;45:1381-8.

7 Viale G, Bosari S, Mazzarol G, Galimberti V, Luini A, Veronesi P, Paganelli G, Bedoni M, Orvieto $\mathrm{E}$ : Intraoperative examination of axillary sentinel lymph nodes in breast carcinoma patients. Cancer 1999;85:2433-8.
8 Luini A, Caldarella P, Gatti G, Veronesi P, Vento AR, Naninato P, Arnone P, Sangalli C, Brenelli F, Sosnovskikh I, Peradze N, Dussan Luberth CA, Viale G, Paganelli G: The sentinel node biopsy under local anesthesia in breast cancer: advantages and problems, how the technique influenced the activity of a breast surgery department; update from the European Institute of Oncology with more than 1,000 cases. Breast 2007; 16:527-32.

$\checkmark 9$ Yen TW, Hunt KK, Ross MI, Mirza NQ, Babiera GV, Meric-Bernstam F, Singletary SE, Symmans WF, Giordano SH, Feig BW, Ames FC, Kuerer HM: Predictors of invasive breast cancer in patients with an initial diagnosis of ductal carcinoma in situ: a guide to selective use of sentinel lymph node biopsy in management of ductal carcinoma in situ. J Am Coll Surg 2005;200:516-26.

10 Intra, Mattia MD; Rotmensz, Nicole MSc; Veronesi, Paolo MD; Colleoni, Marco MD; Iodice, Simona MSc; Paganelli, Giovanni MD; Viale, Giuseppe MD, FRCPath, Veronesi, Umberto MD: Sentinel node biopsy is not a standard procedure in ductal carcinoma in situ of the breast: the experience of the European Institute of Oncology on 854 patients in 10 years. Ann Surg 2008;247:315-9.

11 Jackman RJ, Burbank F, Parker SH, Evans WP 3rd, Lechner MC, Richardson TR, Smid AA, Borofsky HB, Lee CH, Goldstein HM, Schilling KJ, Wray AB, Brem RF, Helbich TH, Lehrer DE, Adler SJ: Stereotactic breast biopsy of nonpalpable lesions: determinants of ductal carcinoma in situ underestimation rates. Radiology 2001;218:497502.

12 Cox CE, Cox JM, Ramos D, Meade TL: Intramammary sentinel lymph nodes: what is the clinical significance? Ann Surg Oncol 2008;15:1273-4.

13 Galimberti V, Veronesi P, et al.: Stage migration after biopsy of internal mammary chain lymph nodes in breast cancer patients. Ann Surg Oncol 2002;9:924-8.

14 Intra M, Garcia-Etienne CA, Renne G, Trifirò G, Rotmensz N, Gentilini OD, Galimberti V, Sagona A, Mattar D, Sangalli C, Gatti G, Luini A, Veronesi U: When sentinel lymph node is intramammary. Ann Surg Oncol 2008;15:1304-8.
15 Shrenk P, Wayand W: Sentinel-node biopsy in axillary lymph-node staging for patients with multicentric breast cancer. Lancet 2001;357:122.

16 Kumar R, Jana S, Heiba SI, Dakhel M, Axelrod D, Siegal B, et al.: Retrospective analysis of sentinel node localization in multifocal, multicentric, palpable, or non palpable breast cancer. J Nucl Med 2003;44:7-10.

17 Gentilini O, Trifirò G, Soteldo J, Luini A, Intra M, Galimberti V, Veronesi P, Silva L, Gandini S, Paganelli G, Veronesi U: Sentinel lymph node biopsy in multicentric breast cancer. The experience of the European Institute of Oncology. Eur J Surg Oncol 2006;32:507-10.

18 Viale G, Zurrida S, Maiorano E, Mazzarol G, Pruneri G, Paganelli G, Maisonneuve P, Veronesi U: Predicting the status of axillary sentinel lymph nodes in 4,351 patients with invasive breast carcinoma treated in a single institution. Cancer 2005;103:492-500.

19 Intra M, Veronesi P, Gentilini OD, Trifirò G, Berrettini A, Cecilio R, Colleoni M, Rietjens M, Luini A, Paganelli G, Veronesi U: Sentinel lymph node biopsy is feasible even after total mastectomy. J Surg Oncol 2007;95:175-89.

20 Rodriguez Fernandez J, Martella S, Trifirò G, Caliskan M, Chifu C, Brenelli F, Botteri E, Rossetto F, Rotmensz N, Rietjens M, Veronesi P: Sentinel node biopsy in patients with previous breast aesthetic surgery. Ann Surg Oncol 2009;16:989-92.

21 Intra M, Trifirò G, Galimberti V, Gentilini O Rotmensz N, Veronesi P: Second axillary sentinel node biopsy for ipsilateral breast tumour recurrence. Br J Surg 2007;94:1216-9.

22 Gentilini O, Cremonesi M, Trifirò G, Ferrari M, Baio SM, Caracciolo M, et al.: Safety of sentinel node biopsy in pregnant patients with breast cancer. Ann Oncol 2004;15:1348-51.

23 Gentilini O, Cremonesi M, Toesca A, Colombo N, Peccatori F, Sironi R, Sangalli C, Rotmensz N, Pedroli G, Viale G, Veronesi P, Galimberti V, Goldhirsch A, Veronesi U, Paganelli G: Sentinel lymph node biopsy in pregnant patients with breast cancer. Eur J Nucl Med Mol Imaging 2010;37:7883. 
24 Breslin TM, Cohen L, Sahin A, et al.: Sentinel lymph node biopsy is accurate after neoadjuvant chemotherapy for breast cancer. J Clin Oncol 2000;18:3480-6.

25 Schwartz GF, Meltzer AJ: Accuracy of axillary sentinel lymph node biopsy following neoadjuvan (induction) chemotherapy for carcinoma of the breast. Breast J 2003;9:374-9.

-26 Mamounas EP, Brown A, Anderson S, et al. Sentinel node biopsy after neoadjuvant chemotherapy in breast cancer: results from National Surgical Adjuvant Breast and Bowel Project Protocol B-27. J Clin Oncol 2005;23:2694-702.

27 Xing YMF, Cox DD, Kuerer HM, et al.: Metaanalysis of sentinel lymph node biopsy after preoperative chemotherapy in patients with breast cancer. Br J Surg 2006;93:539-46.

28 Veronesi P, Gentilini O, Fernandez JR, Magnoni F: Breast conservation and sentinel lymph node biopsy after neoadjuvant systemic therapy. Breast 2009;18(suppl 3):S90-2.
29 Gentilini O, Chagas E, Zurrida S, Intra M, De Cicco C, Gatti G, Silva L, Renne G, Cassano E, Veronesi U: Sentinel lymph node biopsy in male patients with early breast cancer. Oncologist 2007;12:512-5.

30 Veronesi U, Paganelli G, Viale G, Luini A, Zurrida S, Galimberti V, Intra M, Veronesi P, Robertson C, Maisonneuve P, Renne G, De Cicco C, De Lucia F, Gennari R: A randomized comparison of sentinel-node biopsy with routine axillary dissection in breast cancer. N Engl J Med 2003;349:54653.

31 Rudenstam CM, Zahrieh D, Forbes JF, Crivellari D, Holmberg SB, Rey P, Dent D, Campbell I, Bernhard J, Price KN, CastiglioneGertsch M, Goldhirsch A, Gelber RD, Coates AS; International Breast Cancer Study Group: Randomized trial comparing axillary clearance versus no axillary clearance in older patients with breast cancer: first results of International Breast Cancer Study Group Trial 10-93. J Clin Oncol 2006;24:337-44.
32 Veronesi U, Orecchia R, Zurrida S, Galimberti V, Luini A, Veronesi P, Gatti G, D'Aiuto G, Cataliotti L, Paolucci R, Piccolo P, Massaioli N, Sismondi P, Rulli A, Lo Sardo F, Recalcati A, Terribile D, Acerbi A, Rotmensz N, Maisonneuve $\mathrm{P}$ : Avoiding axillary dissection in breast cancer surgery: a randomized trial to assess the role of axillary radiotherapy. Ann Oncol 2005;16:383-8.

33 Straver ME, Meijnen P, van Tienhoven G, van de Velde CJ, Mansel RE, Bogaerts J, Demonty G, Duez N, Cataliotti L, Klinkenbijl J, Westenberg HA, van der Mijle $H$, Hurkmans C, Rutgers EJ: Role of axillary clearance after a tumor-positive sentinel node in the administration of adjuvant therapy in early breast cancer. J Clin Oncol 2010;28:731-7.

44 Giuliano AE, Hunt KK, Ballman KV, Beitsch PD, Whitworth PW, Blumencranz PW, Leitch AM, Saha S, McCall LM, Morrow M: Axillary dissection vs. no axillary dissection in women with invasive breast cancer and sentinel node metastasis: a randomized clinical trial. JAMA 2011;305:569-75. 